\title{
CONCEPÇÕES E ITINERÁRIOS TERAPÊUTICOS DE PESSOAS EM SOFRIMENTO PSÍQUICO EM CONTEXTOS QUILOMBOLAS
}

\author{
ITINERARIOS TERAPÉUTICOS Y CONCEPCIONES DE PERSONAS \\ EN SUFRIMIENTO PSÍQUICO EN CONTEXTOS QUILOMBOLAS \\ CONCEPTIONS AND THERAPEUTIC ITINERARIES OF PEOPLE \\ IN PSTCHOLOGICAL DISTRESS IN QUILOMBOLA CONTEXTS
}

\section{Danila Cristiny de Araújo Moura Aciole e Josevânia da Silva²}

${ }^{1}$ Centro Universitário Maurício de Nassau, Caruaru/PE, Brasil

${ }^{2}$ Universidade Estadual da Paraíba, Campina Grande/PB, Brasil

\begin{abstract}
RESUMO: O estudo teve por objetivo analisar as concepções sobre o sofrimento psíquico e os cuidados em saúde mental na perspectiva de pessoas com diagnóstico de transtorno mental, residentes em comunidades quilombolas. Trata-se de uma pesquisa com abordagem qualitativa. Participaram nove pessoas de duas comunidades quilombolas do interior do Estado de Pernambuco. Os dados foram coletados através de questionário sociodemográfico e uma entrevista do tipo relato de vida e analisados a partir da Análise de Conteúdo Temática. As categorias temáticas versaram sobre o sofrimento psíquico e as estratégias de cuidado utilizadas pelos participantes no cuidado em saúde mental. Dentre os itinerários terapêuticos dos sujeitos, destacam-se estratégias pautadas no saber biomédico e o cuidado baseado no saber popular.
\end{abstract}

PALAVRAS-CHAVE: Saúde mental; Itinerários terapêuticos; Quilombolas.

RESUMEN: El estudio tuvo como objetivo analizar las concepciones sobre el distrés psicológico y el cuidado de la salud mental desde la perspectiva de personas diagnosticadas con trastornos mentales, residentes en comunidades quilombolas. Se trata de una investigación con enfoque cualitativo. Participaron nueve personas de dos comunidades quilombolas del interior del estado de Pernambuco. Los datos fueron recolectados a través de un cuestionario sociodemográfico y una entrevista de informe de vida y analizados usando el análisis de contenido temático. Las categorías temáticas se ocuparon de la angustia psicológica y las estrategias de atención utilizadas por los participantes en el cuidado de la salud mental. Entre los itinerarios terapéuticos de los sujetos destacan las estrategias basadas en el conocimiento biomédico y el cuidado basado en el conocimiento popular.

PALABRAS CLAVE: Salud mental; Itinerarios terapéuticos; Quilombolas.

ABSTRACT: The study aimed to analyze the conceptions about psychological distress and mental health care from the perspective of people diagnosed with mental disorder living in quilombola communities. This is a research with qualitative approach, in which participated nine people from two quilombola communities in the interior of the state of Pernambuco. The data was collected through a socio-demographic questionnaire and a life report interview, and analyzed using thematic content analysis. The thematic categories regarded the psychological distress and the care strategies used by the participants in mental health care. Among the people's therapeutic itineraries, strategies based on biomedical knowledge and care based on popular knowledge are highlighted.

KEYWORDS: Mental health; Therapeutic itineraries; Quilombola. 


\section{Introdução}

As diversas concepções sobre saúde mental têm relação com a complexidade dos aspectos que caracterizam esse fenômeno, os quais são perpassados por elementos culturais, sociais, subjetivos, dentre outros. Saúde mental pode ser compreendida a partir da relação dialética estabelecida entre a esfera individual/subjetiva e o contexto ambiental/social, podendo interferir e influenciar no estado de equilíbrio psíquico das pessoas (Tonin \& Barbosa, 2018).

A saúde mental está diretamente relacionada à qualidade de vida (Sardinha et al., 2019), envolvendo questões de ordem genética, de gênero e raça/etnia, bem como a capacidade de adaptação e resiliência, de criação de laços afetivos e sociais (Batista \& Rocha, 2019). Inclui, ainda, questões relativas ao contexto estrutural nos quais as pessoas estão inseridas, tais como: empregabilidade e acesso às políticas públicas (saúde, educação, habitação, condições de moradia etc.) (Batista \& Rocha, 2020).

As condições precárias de existência impostas ao sujeito, e até mesmo pela constante exposição ao racismo, preconceito, vulnerabilidade, violência e todas as formas de exclusão e opressão, geram sofrimento psíquico (Viapiana, Gomes, \& Albuquerque, 2018). Dessa forma, o reconhecimento de como os determinantes sociais atravessam e interferem no processo de saúde e doença dos grupos populacionais se torna ferramenta fundamental para a construção de estudos que versem sobre o cuidado em saúde mental, e principalmente para fundamentar as práticas que são desenvolvidas pelos profissionais de saúde nos territórios (Costa \& Scarcelli, 2016).

A Política nacional de Saúde integral da População negra (PnSiPn) foi aprovada só em 2007, apresentando-se como uma resposta às desigualdades em saúde que acometem a população negra, bem como evidenciando o reconhecimento de que as suas condições de vida resultam de injustos processos sociais, culturais e econômicos, que colaboram para as iniquidades em saúde (Ministério da Saúde, 2017). Ademais, no cenário brasileiro, existe certo desconhecimento ou até mesmo práticas enviesadas quanto às questões de saúde mental da população negra, especialmente em relação às comunidades quilombolas (Nascimento \& Leão, 2019). Por exemplo, são escassos os estudos e dados epidemiológicos que identifiquem e caracterizem esse grupo populacional e suas demandas de saúde mental (Nascimento \& Leão, 2019).

A população brasileira é composta, majoritariamente, por pretos e pardos (IBGE, 2010). Contudo, verifica-se uma subnotificação quanto ao quesito raça/cor nas notificações sobre o perfil dos usuários atendidos em Centros de Atenção Psicossocial (CAPS) (Silva, Barros, Azevedo, Batista, \& Policarpo, 2017). E quando esses dados aparecem, não são enfatizados nas análises sobre os indicadores de saúde mental.

Esse fato é evidenciado por outros estudos (Mussi, Rocha, \& Alves, 2019; Veiga, 2019) que apontam para quão negligenciadas são as questões de saúde mental da população negra, no Brasil. Os dados sobre a prevalência de transtornos mentais nesse grupo populacional são imprecisos e subnotificados (Mussi et al., 2019). Esses dados também são ausentes nas plataformas do Ministério da Saúde através do DATASUS (Departamento de Informática do Sistema Único de Saúde), não podendo ser analisados e, consequentemente, dificultando a construção e efetivação de Políticas Públicas. 
Estudos empíricos no âmbito da saúde mental de pessoas residentes em comunidades quilombos são necessários na medida em que dão visibilidade às demandas desse grupo populacional. Mais que isso, colaboram para escutar suas vozes e possibilitar o reconhecimento da potencialidade das práticas de cuidado representada pelo saber popular produzido dentro dos seus territórios.

As estratégias de cuidado em saúde mental existentes em contextos quilombolas perpassam desde os recursos e mecanismos formais e se estendem até as práticas cotidianas de cuidado, como o uso de chá e ervas medicinais e as práticas religiosas (Badke, Budó, Alvim, Zanetti, \& Heisler, 2012). Essas estratégias de cuidado apontam para relações afetivas estabelecidas dentro dos territórios tradicionais, pois elas falam das relações familiares, das crenças e tradições, da ancestralidade e da relação própria estabelecida pelo indivíduo e a terra como recurso terapêutico (Badke et al. 2012).

Em decorrência de todo processo de exclusão, preconceito e criminalização sofrida pela população negra, especialmente em territórios quilombolas, o exercício das práticas tradicionais de cuidado e a utilização da religiosidade têm se tornado objeto de disputa dentro das comunidades. Por essa razão, frequentemente, verifica-se que tais práticas não são referenciadas pelos sujeitos como recurso terapêutico de cuidado em saúde (Antonio, Tesser, \& Moretti-Pires, 2013). Outro aspecto que colabora para isto é ênfase na valorização do saber biomédico e da indústria farmacêutica como modalidade válida de cuidado em saúde. Apesar disso, se verifica a circulação dos saberes tradicionais dentro da comunidade, num movimento de quase resistência à monopolização do cuidado em saúde pautado no saber biomédico, que coexiste com os saberes tradicionais.

Com a criação da Política Nacional de Práticas Integrativas e Complementares (PNPIC), no SUS (Sistema Único de Saúde), pela Portaria do Ministério da Saúde (MS) n. 971, de 03 de maio de 2006, dá-se um passo importante no principal sistema e estrutura gestora de cuidado em saúde. Em parte, essa política procurou conciliar as várias modalidades e recursos terapêuticos, tendo em vista possibilitar o diálogo entre aquilo que advém dos estudos científicos e do saber criado e executado no cotidiano dos sujeitos (Ministério da Saúde, 2006). Nesse sentido, este estudo teve por objetivo analisar as concepções sobre o sofrimento psíquico e os cuidados em saúde mental na perspectiva de pessoas com diagnóstico de transtorno mental, residentes em comunidades quilombolas. 


\section{Método}

\section{Tipo de estudo}

A pesquisa se caracteriza como sendo exploratória, descritiva e transversal, com abordagem qualitativa.

\section{Participantes}

Participaram do estudo, de forma não probabilística e por conveniência, nove moradores de duas comunidades quilombolas do estado de Pernambuco. As comunidades quilombolas e os participantes foram identificados por nomes fictícios, tendo em vista preservar o anonimato dos participantes.

Dentre os participantes, seis residiam na comunidade quilombola Estrada Estreita e três eram moradores da comunidade quilombola Estrada Branca. Esses participantes possuíam histórico de sofrimento psíquico e foram diagnosticados com transtornos mentais. O contato com os participantes foi realizado com ajuda dos líderes comunitários de ambas as comunidades e da agente comunitária de saúde (ACS) da comunidade Estrada Estreita. Para delimitar o número de participantes, foi utilizado o critério de saturação das entrevistas.

Como critério de inclusão dos participantes, considerou-se os seguintes aspectos: (a) possuir idade igual ou maior que 18 anos; (b) residir em comunidade quilombola; (c) pessoas em sofrimento psíquico, que tenha histórico de internação e/ou acompanhamento psiquiátrico, acompanhamento em Centro de Atendimento Psicossocial (CAPS), ou faça uso de psicofármacos há mais de um ano, levando em consideração o grau de comprometimento cognitivo e social dessas pessoas. Este último critério foi observado mediante a colaboração do ACS da comunidade e da Líder Comunitária, que conheciam as famílias e a situação de saúde da comunidade.

\section{Instrumentos}

Para coleta de dados foi utilizado um questionário sociodemográfico e entrevista. A modalidade de entrevista escolhida para coleta de dado foi a história oral, que se apresenta em formas distintas, a saber: a História Vida, na qual o entrevistado é levado a contar livremente sua vida, trazendo em seu relato elementos que sejam significativos a sua história (Lang, Campos, \& Demartini, 2010); o Relato de vida, com caráter menos amplo, que solicita do entrevistado focar determinados aspectos de sua vida; e, por último, o Depoimento oral, que busca focalizar a participação do entrevistado em determinada instituição ou sua vivência em uma situação específica (Lang et al., 2010). Neste estudo, foi utilizado Relato de vida, uma vez que essa modalidade de entrevista se adequa às especificidades dos participantes e ao objetivo do estudo. A entrevista do tipo Relato de vida possibilitou apreender os sentidos construídos pelas pessoas em sofrimento psíquico a partir do relato de temáticas específicas de sua trajetória de vida (Fernandes, 1995). 


\section{Procedimentos}

A coleta de dados ocorreu entre os meses de setembro e outubro de 2018. Inicialmente, foi realizado o contato com as lideranças comunitárias para poder ter acesso às pessoas em sofrimento psíquico, considerando os critérios de inclusão. Depois, foram realizadas visitas ao domicílio dos participantes. Na ocasião, foram explicitados os objetivos da pesquisa e a disponibilidade para a participação voluntária. Em seguida, foi solicitada a assinatura do Termo de Consentimento Livre e Esclarecido (TCLE) e do Termo de gravação de voz. Depois, foi realizada a aplicação do questionário sociodemográfico, seguido da entrevista de relato de vida. Como esse método possui caráter amplo e requer, do participante, reviver situações dolorosas de sua trajetória, a entrevista foi realizada de forma que esses pudessem ser acolhidos e respeitados em seu tempo de fala.

A entrevista foi realizada pela pesquisadora responsável, de forma individual e reservada, em local escolhido pelo entrevistado e com duração média de uma hora. Os dados foram gravados para transcrição e posterior análise.

\section{Análise dos dados}

Os dados decorrentes das entrevistas foram analisados a partir da análise de conteúdo do tipo categorial temática, conforme proposta de Bardin (2011). A análise de conteúdo corresponde a um conjunto de técnicas de análise das comunicações, visando a obter indicadores (quantitativos ou não) que permitam a inferência de conhecimentos relativos às condições de produção/recepção (variáveis inferidas) das mensagens enunciadas. Para tanto, realizaram-se as três etapas necessárias para a identificação das categorias temáticas, a saber: pré-análise, exploração do material e tratamento dos resultados (a inferência e a interpretação).

\section{Aspectos éticos}

Durante o desenvolvimento desta pesquisa, todos os participantes tiveram acesso e assinaram o Termo de Consentimento Livre e Esclarecido (TCLE). Cabe salientar que o desenvolvimento desta pesquisa foi custeado por financiamento próprio e teve sua aprovação de um Comitê de Ética e Pesquisa, sob o parecer n. 2.925.682, cumprindo-se os preceitos éticos da pesquisa envolvendo seres humanos, conforme determinado pela Resolução n. 466/2012, do Conselho Nacional de Saúde (CNS, 2012). 


\section{Resultados e discussão}

Em relação ao perfil sociodemográfico, a idade dos participantes variou de 23 a 56 anos. Dentre os nove entrevistados, cinco eram do sexo feminino, seis se declararam católicos e três evangélicos. Quanto ao estado civil declarado, três eram solteiros, cinco eram casados e um era divorciado. Os sete participantes que se declararam negros foram os mesmos que também se declararam quilombolas. Outras informações estão na Tabela 1.

Tabela 1: Perfil sociodemográfico e clínico dos sujeitos em sofrimento psíquico.

\begin{tabular}{|c|c|c|}
\hline \multicolumn{2}{|c|}{ Variáveis } & \multirow{2}{*}{$\frac{\text { Frequência }}{01}$} \\
\hline \multirow{3}{*}{ Raça } & Parda & \\
\hline & Preta & 07 \\
\hline & Outra & Vermelha \\
\hline \multirow{3}{*}{ Se reconhece quilombola } & Sim & 07 \\
\hline & Não & 01 \\
\hline & Não sabe & 01 \\
\hline \multirow{4}{*}{ Escolaridade } & Analfabeto & 02 \\
\hline & Sabe ler e escrever & 02 \\
\hline & Ensino fundamental completo & $\mathrm{O} 2$ \\
\hline & Ensino Médio completo & 03 \\
\hline \multirow{4}{*}{ Renda } & Salário Mínimo & 03 \\
\hline & < Salário Mínimo & 03 \\
\hline & > Salário Mínimo & 01 \\
\hline & Sem renda & 02 \\
\hline \multirow{5}{*}{ Função Laboral } & Agricultor(a) & 02 \\
\hline & Dona de Casa & 01 \\
\hline & Vendedor(a) & 01 \\
\hline & Agente Comunitário de Saúde & 02 \\
\hline & Não Possui & 03 \\
\hline \multirow{2}{*}{ Benefício Social } & Sim & 04 \\
\hline & Não & 05 \\
\hline \multirow{2}{*}{$\begin{array}{c}\text { Histórico de internação } \\
\text { psiquiátrica }\end{array}$} & Sim & 04 \\
\hline & Não & 05 \\
\hline \multirow{2}{*}{$\begin{array}{l}\text { Uso contínuo de } \\
\text { medicação }\end{array}$} & Sim & 07 \\
\hline & Não & 02 \\
\hline \multirow{2}{*}{$\begin{array}{l}\text { Acompanhamento } \\
\text { psiquiátrico }\end{array}$} & Sim & 06 \\
\hline & Não & 03 \\
\hline
\end{tabular}


Sobre o histórico clínico dos entrevistados, apenas dois alegaram não fazer uso contínuo de medicação. Contudo, no momento da entrevista, relataram que fazem uso da medicação quando há sinalização de crise. Dentre os entrevistados, quatro participantes viveram a experiência de internamentos em instituição psiquiátrica. Desses, apenas um era morador da comunidade quilombola Estrada Branca.

A análise de conteúdo do tipo categorial temática, realizada com os dados decorrentes das entrevistas, evidenciou duas categorias temáticas e sete subcategorias, as quais abarcaram 103 unidades de conteúdo, conforme demonstrado na tabela abaixo.

Tabela 2: Categorias, subcategorias e unidade de conteúdo.

Categorias

\begin{tabular}{cccc}
\hline \multirow{2}{*}{$\begin{array}{c}\text { Sofrimento } \\
\text { Psíquico }\end{array}$} & Desconhecimento sobre o diagnóstico & 06 & \\
& Explicações & 04 & $20,4 \%$ \\
Estigmas e preconceitos & 11 & \\
terapêuticos & Vivência em hospital Psiquiátrico & 06 & \\
& Cuidados formais e medicação & 31 & \\
& Saber popular e crenças religiosas & 27 & $79,6 \%$ \\
& Atividades Ocupacionais & 18 & \\
& TOTAL & 103 & $100 \%$
\end{tabular}

UC: unidade de conteúdo; f: frequência; \%: porcentagem.

\section{Sofrimento psíquico}

Esta categoria temática possui como centralidade os conteúdos relativos à compreensão sobre o sofrimento psíquico, correspondendo a 20,4\% das unidades de conteúdo. Os relatos evidenciaram o diagnóstico como algo de difícil compreensão para os participantes, bem como apontaram as explicações que eles davam para o sofrimento psíquico e as vivências associadas ao estigma da loucura.

Na subcategoria Desconhecimento sobre o diagnóstico, os relatos demonstraram que, inicialmente, os participantes não compreendiam bem o que estavam sentido. Em alguns casos, o entendimento sobre o sofrimento era limitado pela ausência das informações necessárias.

Eu não sabia o que era, não sabia o que era que tava acontecendo comigo. Aí, fiquei perdendo o sono, levei um susto. (...) Eu não sabia o que tava acontecendo dentro de mim. (Zumbi dos Palmares, Comunidade quilombola Estrada Estreita)

Não sabia. Ele [psiquiatra] me dava remédio lá, mas num me explicaram não. (Luiza Mahin, Comunidade quilombola Estrada Estreita) 
Em muitos casos, os profissionais de saúde não dão as informações necessárias ao usuário, corroborando outros estudos (Dimenstein, Leite, Macedo, \& Dantas, 2017). O diagnóstico psiquiátrico foi (e ainda é) utilizado como uma forma de legitimação do saber médico (Zambillo, Palombini, \& Ecker, 2018). O diagnóstico, então, acaba por servir de instrumento de operacionalização da exclusão, ocorrendo, assim, um distanciamento da realidade cotidiana do sujeito que o recebe. Por sua vez, a pessoa que sofre é um sujeito de direitos e, portanto, não pode ser colocado como expectador das estratégias de cuidado da sua própria saúde, mas deve participar como agente ativo no processo de cuidado (Silva \& Andrade, 2018).

Não obstante, os participantes procuraram compreender e explicar o sofrimento psíquico, conforme a subcategoria Explicações. $\mathrm{O}$ entendimento do processo de adoecimento parece se tornar mais compreensível se este for dado através de uma explicação que leve em consideração algum aspecto orgânico/físico ou de caráter objetivo (Cardoso, Oliveira, \& Piani, 2016).

A partir dos relatos dos participantes, foi possível observar explicações que incorporam questões místicas, que têm por finalidade facilitar a compreensão do processo de adoecimento. Esse aspecto pode ser observado no relato de Benedito Meia-Légua (comunidade quilombola Estrada Branca): "Me alembro que eu tava na roça, levei uma chuvada quando cheguei em casa me deu esse problema”. Além disso, dentre as explicações, os relatos também demonstraram que os sujeitos reconhecem a relação entre condições de vida e sofrimento psíquico:

A gente trabalhava muito, passava muita fome. Trabalhava muito, muito mesmo, com uma garra da poxa. Trabalhando pra sustentar a família. Aí, passado um tempo, começemo se envolver com cachaça, com droga. Aí, a gente não se deu conta que a bebida tava tomando a gente, tomando nosso cérebro. (Ganga Zumba, Comunidade Quilombola Estrada Estreita).

A compreensão e as explicações que cada pessoa constrói, durante sua trajetória de vida, sobre o sofrimento psíquico decorrem do seu sistema simbólico e cultural, bem como em razão das condições de vida. Tais modelos explicativos, ainda que possuam elementos místicos, dão e fazem sentido aos sujeitos que os narram. Considerar que essas construções estão situadas no campo vivencial dos sujeitos possibilita a condução dos itinerários terapêuticos (Fernandes \& Santos, 2019)

A subcategoria Estigmas e preconceitos abarcou as narrativas dos participantes sobre suas vivências ante o sofrimento psíquico. Nos relatos, é possível identificar que o sofrimento psíquico, por vezes, é caracterizado a partir de estereótipos e preconceitos, com sendo "safadeza" ou "falta de homem".

Eu também já escutei que depressão não é doença. Escutei isso há muitos anos, que depressão não é doença, é servegonhesa, é safadeza. (Dandara, comunidade quilombola do Estrada Estreita).

Até o médico disse, na minha cara, ou você deixa de frescura ou eu the interno. Então aquilo pra mim foi mais um baque. Porque a família também, na época, alguns diziam que era falta de homem: "ela não tá com depressão, é falta de homem. Então..., pronto! (Zacimba Gaba, comunidade quilombola Estrada Estreita). 
Historicamente, o transtorno mental foi associado a imagens como possessão demoníaca, agressividade, perigo, frescura, entre outros estereótipos (Nascimento \& Leão, 2019). Nas narrativas, por exemplo, verifica-se a associação entre o adoecimento psíquico e explicações de cunho machista direcionadas às mulheres (Furtado, Saldanha, Moleiro, \& Silva, 2019). Os estereótipos negativos, além de legitimar relações de poder, têm por objetivo invalidar o sofrimento psíquico, o que acaba por fragilizar, ainda mais, as pessoas que já não possuem uma compreensão sobre o seu processo de adoecimento, como já evidenciado (Zambillo et al., 2018).

Estes resultados demonstram que os sujeitos são confrontados com narrativas explicativas que potencializam o sofrimento psíquico vivenciado. São descrições que evidenciam estigmas sobre a loucura e apontam para o preconceito subjacente, os quais, historicamente, delegaram ao sujeito com diagnóstico de transtorno mental um lugar de exclusão, isolamento social e de (des)razão (Netto \& Alves, 2012).

\section{Itinerários terapêuticos}

Esta categoria foi a que apresentou maior frequência de unidades de conteúdo (79,6\%), as quais abarcaram quatro subcategorias: Vivência em hospital Psiquiátrico; Cuidados formais e medicação; Saber popular e crenças religiosas e Atividades ocupacionais. A partir dos relatos, foi possível identificar os itinerários terapêuticos percorridos.

A concepção de itinerários terapêuticos em saúde pressupõe que os sujeitos, ao tentarem retornar ao seu estado de saúde, adotam uma postura dinâmica que os implica a mobilizar-se em múltiplas direções (Gerhardt, 2006). Os "itinerários terapêuticos são constituídos por todos os movimentos desencadeados por indivíduos ou grupos na preservação ou recuperação da saúde, que podem mobilizar diferentes recursos que incluem desde os cuidados caseiros e práticas religiosas até os dispositivos biomédicos predominantes" (Cabral, Martinez-Hemáez, Andrade, \& Cherchiglia, 2011 , p. 4434).

Na tentativa de cuidar de sua saúde, as pessoas desenham múltiplas estratégias, perpassando por diferentes sistemas de cuidados (formais e informais). Esse desenho é delineado a partir dos recursos sociais disponíveis e da resolutividade que cada sistema possibilita ao sujeito (Cardoso, Oliveira, \& Piani, 2016). Nas suas trajetórias em busca de cuidado, os participantes narram muito mais que escolhas, mas trazem à tona suas condições de vida, vulnerabilidades e dificuldades de acessarem o cuidado integral em saúde (Fernandes, 2016).

Na subcategoria Vivência em hospital Psiquiátrico, a internação psiquiátrica apareceu como um dos recursos utilizados pelos participantes. Dos nove entrevistados, quatro passaram por internamento em hospitais psiquiátricos. No entanto, todos os entrevistados possuem algum tipo de vivência de internamento em decorrência do adoecimento psíquico, especialmente em hospitais gerais. Dalmolin (2006) afirma que tais dispositivos aparecem como a "porta de entrada" mais acionada por familiares e cuidadores como forma de conter a crise, após terem recorrido a outros recursos informais.

Nas quatro narrativas sobre a vivência do internamento, não houve consenso sobre o tipo de assistência prestada. Embora um participante tenha relatado uma experiência positiva, no momento específico da pergunta sobre o internamento, a maioria das narrativas evidenciou vivências dolorosas. 
Eu não gostei não. Eu fiquei 45 dias, foi triste, foi muito triste. Foi desumano o que fizeram comigo (...). Era horrível demais. Lá é horrível, era muita zoada, muito barulho, ninguém dormia, era muito roubo, era muita briga, muita discussão. (Ganga Zumba, comunidade quilombolas Estrada Estreita)

Não foi experiença ruim, não. Lá eu tinha alimentação certinha, o lanche, a refeição. Comia bastante, brincava de bola, eles brincavam, batia papo mais os amigos lá, mais os pacientes. (Zumbi dos Palmares, comunidade quilombola Estrada Estreita)

Ao mesmo tempo que na narrativa de Zumbi ele compreende a internação numa perspectiva positiva, em outra fala, quando questionado sobre o período de alta, ele relata a importância da liberdade, e reconhece o processo de internamento psiquiátrico como um aprisionamento que limita a existência do sujeito. Esse aspecto é apontado por Goffman (1961) quando discorre sobre a mortificação do eu ocorrida durante o período de internação, no sujeito é despersonificado/descaracterizado e enquadrado num padrão institucional altamente violento.

Eu me senti, me senti livre, quando eu saí da providência. Eita! Agora eu tô livre. Agora eu posso fazer as coisas que eu quero, eu posso passear, agora pra o futebol. (...) e se cuidar mais pra não pra não cair de novo. Eu pensei também quando tava ali, tava preso, tava um passarin preso. (...) Hoje posso sair pra uma brincadeira, diversão. Lá não podia, né? Lá não podia. (Zumbi dos Palmares, comunidade quilombolas Estrada Estreita)

Na subcategoria Cuidados formais e medicação, destaca-se a busca de cuidado através da medicação e consulta médica (na rede pública e privada), apresentando 31 unidades de conteúdo, sendo referenciado como um dos recursos acionado pelos participantes e familiares em momentos de crise.

O itinerário percorrido pelos participantes, dentro do sistema formal, tem início com a busca por consulta médica, não necessariamente o especialista em saúde mental (psiquiatra). Outros especialistas foram acionados, como neurologista e clínico geral. Frequentemente, este primeiro contato ocorre através do setor privado e só ao longo do processo de adoecimento é que os sujeitos recorrem ao SUS (Dantas, Dimenstein, Leite, Macedo, \& Belarmino, 2020; Furtado et al., 2019).

Eu procurei o médico logo de cara. Eu procurei um psiquiatra, um psiquiatra não, o neurologista. Eu fui logo pra o neuro, onde eu tive. Ai entrei em tratamento. Ai começava tendo crises, tinha mais entrada no hospital do que tudo nesse mundo. (Dandara, comunidade quilombola Estrada Estreita)

Sobre os percursos trilhados dentro do sistema formal, a medicação aparece como estratégia recorrente, sendo uma das principais formas de auxílio para o sujeito lidar com as consequências do sofrimento psíquico (Lima \& Ferreira, 2018). O uso contínuo da medicação foi referenciado por sete entrevistados, e os demais apontaram que, em momentos de crise, recorrem a esse tipo de estratégia para lidarem com os sintomas da doença.

A prática da automedicação também apareceu nas narrativas dos entrevistados. Em geral, os participantes já fizeram o uso de psicofármaco indicado por um vizinho ou familiar. As pessoas incidem nessa prática seja em decorrência do baixo custo, seja pela 
dificuldade e morosidade para o agendamento com um profissional médico especialista (Fernandes, 2016). Outra dificuldade é a inadequação da medicação às quais, mesmo sob prescrição médica, os participantes afirmaram que não conseguiram se adaptar. Ademais, como os recursos financeiros são limitados, ocorre certa dificuldade para retornar à consulta com profissional do sistema privado, que são os primeiros a serem procurados.

O saber biomédico, através das tecnologias ditas duras, como o uso de psicofármacos, serviços e equipamentos (Fertonani, Pires, Biff, \& Scherer, 2015), tem se destacado cada vez mais em comunidades tradicionais. Contudo, a partir dos relatos dos participantes, não se verifica, por parte dos profissionais, a inclusão de estratégias de cuidado que emanem do território onde transitam (Dantas et al., 2020).

Não obstante, as pessoas fazem uso de outras formas mais reflexivas de cuidado. Destaca-se, por exemplo, o cuidado baseado no saber popular e em atividades ocupacionais, como o cuidado com a terra. Ao destacar essas estratégias de cuidado, ressalta-se a importância do compartilhamento de crenças, valores e regras nos grupos de pertencimento, uma vez que colaboram para o delineamento dos itinerários terapêuticos (Fernandes \& Santos, 2019). Esses aspectos são evidenciados na subcategoria Saber popular e crenças religiosas, com relatos que versam sobre o uso de benzeduras e chás como uma das alternativas para amenizar o sofrimento psíquico.

Eu tava andando que nem meu pai, todo duro. Aí minha tia correu, percebeu. Ai, deu. Ai, chamou eu atenção, assim: sê quer ir lá em casa, fazer um remédio pra você? Eu disse: quero. Aí, me chamou pra me dar um remédio pra eu. Aí, quando eu cheguei lá, era um banho. Era um banho, um banho de ervas. Ai, deu um banho de ervas. Ai eu esmoreci. Ai, eu me recuperei-me. (Ganga Zumba, comunidade quilombolas Estrada Estreita).

Quando eu tô sem sono, às vezes, quando eu tô agitada, eu faço chá de camomila e bebo pra não ter que tomar remédio. Porque eu tenho uma cartelinha de Rivotril, aí eu já escondi. Já escondi porque, quando eu tô sem sono, que eu tô impaciente, se eu for até ele, eu pego. Ai, eu pego, faço um chá, alguma coisa do tipo pra conseguir dormir. (Zacimba Gaba, comunidade quilombola Estrada Estreita)

A prática das benzeduras é antiga, e era utilizada como alternativa para aquelas populações que não tinha acesso aos mecanismos de saúde convencional, mesmo com o avanço da medicina e a interiorização do saber médico. No cotidiano das comunidades quilombolas, é frequente o uso de ervas medicinais para o tratamento de patologias leves, como dores de cabeça, resfriados e mal-estar (Fernandes, 2016). Essas práticas apresentam-se como movimento de resistência e necessidade no cotidiano, ainda que forma tímida, pois possibilitam o resgate, a reconstrução e atualização de uma memória coletiva.

A partir dos relatos dos participantes, verificou-se que o direcionamento dessas práticas para o cuidado do transtorno mental aparece anteriormente à crise e aos sintomas mais graves. Os entrevistados relatam o uso dos chás e de ervas medicinais como calmantes para diminuir agitação e ajudar no sono, e como uma estratégia de não retornar à medicação controlada. Quando os sintomas são mais graves, os participantes relataram que o uso do chá e das práticas não são suficientes para fazer retornar ao estado de equilíbrio, necessitando, assim, acionarem o sistema de saúde formal. 
Sempre me falam vai tomar chá. Mas se eu tiver nervosa, não vai me acalmar não, nem chá, nem suco, nem nada. Tem que entrar no remédio. Vai me acalmar não. Tem que ser a medicação. (Dandara, comunidade quilombola Estrada Estreita)

Práticas religiosas e/ou espirituais também foram relatadas como estratégia de cuidado à saúde. Ademais, a religiosidade aparece nas narrativas dos entrevistados como modelo explicativo da doença. Verificou-se, nos relatos, que muitas pessoas da comunidade associavam o sofrimento psíquico a uma questão de ordem espiritual.

Só não ajudou mais porque começaram a dizer que era coisa ruim [risos] que tava em mim. Aí, eu peguei e falei: Não! Não é porque não tem condição. Aí, eu peguei e parei. Porque aquilo me deixou um pouco pra baixo também. Porque era mais pela minha história, do que por qualquer coisa espirita. (Zacimba Gaba, comunidade quilombola Estrada Estreita)

A espiritualidade apresenta-se como via de explicação para o adoecimento, mas também como dimensão de acolhimento singular ao seu sofrimento (Cardoso, Oliveira, \& Piani, 2016). Nesse sentido, a religiosidade apareceu como forma de enfrentamento no processo de adoecimento e na busca pela cura e/ou pelo consolo, como evidenciado na narrativa de Ganga Zumba (comunidade quilombola Estrada Estreita): "Ai, me peguei com Deus forte, me peguei com Deus forte. Ai, Ele me levantou. Nossa senhora aparecida. Ai, eu comecei a recuperar”.

As crenças espirituais ajudam no enfrentamento dos agentes estressores e da sobrecarga emocional advindas do adoecimento (Faria \& Seidl, 2005), favorecendo o manejo da esperança e a manutenção do tratamento. Nos relatos, os participantes atribuíram a Deus a cura de suas enfermidades e a superação do adoecimento, colocando a medicação como ferramenta secundária do cuidado em saúde mental. Assim, as crenças espirituais apresentam-se como dimensão a ser considerada para o melhor êxito do cuidado em saúde mental, principalmente em relação à construção dos projetos terapêuticos singulares.

A subcategoria Atividades ocupacionais foi constituída a partir de relatos que versaram sobre o exercício de atividades diárias que geram bem-estar para os sujeitos, como o cuidado com a terra, com os animais e o artesanato. A terra para comunidades tradicionais representa muito mais que a possibilidade de moradia e produtividade. Tem um sentido existencial, ligado a questões de ancestralidade e ao sentimento de pertença (Fernandes, 2016).

Eu me sinto mar melhor dentro dos matos. É..., pronto, é. Eu tô muito agitado? Eu vou me embora trabaiar, oxe. Passo o dia todinho bem assusegado. Ai, chego, tomo banho, me janto, cum pouco durmo a noite todinha. (Ganga Zona, comunidade quilombola Estrada Branca)

O que me ajuda é os afazeres do dia a dia, pintar a casa, brincar com o cachorro, cuidar do jardim, essas coisas. Não fica só no remédio. (Zacimba Gaba, comunidade quilombola Estrada Estreita)

As atividades localizadas no interior do território, e que não demandam de recursos tecnológicos, colaboram e favorecem o cuidado e a promoção de saúde. Nesse sentido, os relatos apontam para a necessidade de um modelo assistencial em saúde mental que invista nas tecnologias leves como ferramenta de cuidado, as quais têm por objetivo 
atender às necessidades das pessoas a partir do campo relacional (Fertonani et al., 2015). Essas práticas já são utilizadas no cotidiano, mas perde força quando confrontada pelo sistema formal.

Os resultados evidenciaram que os participantes, residentes em comunidades quilombolas, compreendem e referenciam o sistema formal de cuidado em saúde mental. Contudo, antes dos sintomas mais graves aparecerem, verificou-se itinerários de cuidado dentro do próprio território. Em parte, isso decorre da falta de assistência das políticas públicas em contextos rurais e, ao mesmo tempo, os itinerários terapêuticos favorecem encontros cotidianos com os agentes de saúde da própria comunidade. Assim, as estratégias de cuidado não são pautadas em ações mecânicas, mas são permeadas por laços afetivos e de solidariedade.

\section{Considerações finais}

Mesmo com a precariedade de equipamentos sociais e a fragilidade/inexistência das Políticas Públicas em comunidades quilombolas, os sujeitos (re)desenharam suas próprias estratégias de cuidado, construindo, assim, itinerários terapêuticos múltiplos e práticas de cuidado resistentes. Além disso, o cuidado formal aparece como um dos modelos assistenciais procurado. Contudo, esse tipo de assistência conflui com outros tipos de práticas de cuidado informais que, em muitos casos, antecedem os cuidados formais.

O estudo possibilitou a escuta das narrativas dos sujeitos que são os mais afetados pela ausência dos mecanismos de cuidado e, mesmo assim, permanecem cuidando de si frente ao descaso do poder público. Por vezes, os itinerários terapêuticos, em comunidades quilombolas, subvertem a lógica biomédica, demonstrando que a integração com os territórios de pertenças e o contato com a terra são terapêuticos e promovem o bem-estar.

Os relatos apontam para a possibilidade (e necessidade) de diálogo entre os saberes formais e informais, uma vez que o encontro desses sistemas produz novos modos de vida e de cuidado em saúde. Esse encontro, no entanto, não ocorre sem tensionamentos e de forma linear; ora se incorporam, ora se negam, num constante movimento de ruptura e reconciliação. É nesse espaço que vivem e resistem as populações quilombolas, dando conta de suas necessidades de saúde e produzindo novas formas de cuidado no cotidiano, com ou sem a presença dos dispositivos formais.

Os resultados apresentados não são passíveis de generalização, uma vez que discorreram sobre as vivências de pessoas residentes em duas comunidades quilombolas da região Nordeste, que possui especificidades no que se refere às crenças populares, crenças espirituais e fragilidades no acesso aos serviços de saúde em contexto rurais. Em estudos futuros, sugere-se considerar outras regiões do país. 


\section{Referências}

Antonio, G. D., Tesser, C. D., \& Moretti-Pires, R. O. (2013). Contribuições das plantas medicinais para o cuidado e a promoção da saúde na atenção primária. Interface-Comunicação, Saúde, Educação, 17(46), 615-633.

Badke, M. R., Budó, M. D. L. D., Alvim, N. A. T., Zanetti, G. D., \& Heisler, E. V. (2012). Saberes e práticas populares de cuidado em saúde com o uso de plantas medicinais. Texto \& Contexto-Enfermagem, 21(2), 363-370. doi: 10.1590/S0104-07072012000200014

Bardin, L. (2011). Análise de conteúdo. São Paulo: Edições 70.

Batista, E. C. \& Rocha, K. B. (2019). Sentidos e Práticas em Saúde Mental em Comunidades Quilombolas no Estado de Rondônia. Psicologia: Ciência e Profissão, 39(nspe.), 22-37. doi: $10.1590 / 1982-3703003222123$

Batista, E. C. \& Rocha, K. B. (2020). Saúde mental em comunidades quilombolas do Brasil: uma revisão sistemática da literatura. Interações (Campo Grande), 21(1), 35-50. doi: 10.20435/ inter.v21i1.2149

Cabral, A. L. L. V., Martinez-Hemáez, A., Andrade, E. I. G., \& Cherchiglia, M. L. (2011). Itinerários terapêuticos: o estado da arte da produção científica no Brasil. Ciência E̊ Saúde Coletiva, 16(11), 4433-4442. doi: 10.1590/S1413-81232011001200016.

Cardoso, M. R. D. O., Oliveira, P. D. T. R. D., \& Piani, P. P. F. (2016). Práticas de cuidado em saúde mental na voz dos usuários de um Centro de Atenção Psicossocial do estado do Pará. Saúde em Debate, 40(109), 86-99. doi: 10.1590/0103-1104201610907.

Conselho Nacional de Saúde. S. (2012). Resolução 466/2012-Normas para pesquisa envolvendo seres humanos. Brasília, DF: Autor. Recuperado de http://conselho.saude.gov.br/resolucoes/2012/Reso466.pdf

Costa, E. S. \& Scarcelli, I. R. (2016). Psicologia, política pública para a população quilombola e racismo. Psicologia USP, 27(2), 357-366. doi: 10.1590/0103-656420130051

Dalmolin, B. M. (2006). Esperança equilibrista: cartografias de sujeitos em sofrimento psíquico. Rio de Janeiro: Fiocruz.

Dantas, C. M. B., Dimenstein, M., Leite, J. F., Macedo, J. P., \& Belarmino, V. H. (2020). Território e determinação social da saúde mental em contextos rurais: cuidado integral às populações do campo. Revista Psicologia Organizações e Trabalho 20(3), 1132-1140.

Dimenstein, M., Leite, J., Macedo, J. P., \& Dantas, C. (2017). Condições de vida e saúde mental em contextos rurais. Serviço Social e Saúde, 16(1), 151-158. doi: 10.20396/sss. v16i1.8651478

Instituto Brasileiro de Geografia e Estatística - IBGE. (2010). Indicadores sociais mínimos. Censo 2010. Recuperado de http://www.ibge.gov.br/home/estatistica/populacao/condicaodevida/indicadoresminimos/default minimos.shtm

Faria, J. B. D. \& Seid1, E. M. F. (2005). Religiosidade e enfrentamento em contex tos de saúde e doença: revisão da literatura. Psicologia: reflexão e crítica, 1 8(3), 381-389. doi: 10.1590/So102$\underline{79722005000300012 .}$.

Fernandes, M. E. (1995). A" história de vida" como instrumento de captação da realidade social. Cadernos Ceru, 6(2), 145-155. 
Fernandes, S. L. (2016) Itinerários terapêuticos e política pública de saúde em uma comunidade quilombola do agreste de Alagoas, Brasil. Tese de Doutorado - Programa de Pós-graduação em Psicologia, Instituto de Psicologia da Universidade de São Paulo, SP.

Fernandes, S. L. \& Santos, A. D. O. D. (2019). Itinerários terapêuticos e formas de cuidado em um quilombo do agreste alagoano. Psicologia Ciência e Profissão, 39(nspe.), 38-52. doi: $10.1590 / 1982-3703003176272$

Fertonani, H. P., Pires, D. E. P., Biff, D., \& Scherer, M. D. A. (2015). Modelo assistencial em saúde: conceitos e desafios para atenção básica brasileira. Ciência E̊ Saúde Coletiva, 20(6), 1869-1878. doi:10.1590/1413-81232015206.13272014

Furtado, F. M. D. S. F., Saldanha, A. A. W., Moleiro, C., \& Silva, J. (2019). Transtornos mentais comuns em mulheres de cidades rurais: prevalência e variáveis correlatas. Saúde e Pesquisa, 12(1), 129-140. doi:10.17765/2176-9206.2019v12n1p129-140

Gerhardt. T. E. (2006). Itinerários terapêuticos em situações de pobreza: diversidade e pluralidade. Cadernos de Saúde Pública, 22(1 1), 2449-2463, doi:10.1590/So102-311X2006001100019.

Goffman, E. (1961). Manicômios, Prisões e Conventos. São Paulo: Editora Perspectiva.

Lang, A. B. D. S. G., Campos, M. C. S., \& Demartini, Z. D. B. F. (2010). História oral, sociologia e pesquisa: a abordagem do CERU. São Paulo: Humanitas/CERU.

Lima, M. F. \& Ferreira, C. B. (2018). Estratégias de enfrentamento de pacientes com transtornos mentais. Revista Pesquisas e Práticas Psicossociais, 13(2), 1-15. Recuperado de http:// pepsic.bvsalud. org/scielo.php? script=sci arttext\&pid=S1809-89082018000200007\&lng=pt\&tlng=pt.

Ministério da Saúde. (2006). Política Nacional de Práticas Integrativas e Complementares no SUS - PNPIC-SUS. Brasília: Autor. Recuperado de http://189.28.128.100/dab/docs/ publicacoes/geral/pnpic.pdf

Ministério da Saúde. (2017). Política Nacional de Saúde Integral da População Negra: uma política para o SUS ( $3^{\mathrm{a}}$ ed.). Brasília: Autor. Recuperado de http://bvsms.saude.gov.br/ bvs/publicacoes/politica nacional saude populacao negra 3d.pdf

Mussi, R., Rocha, S., \& Alves, T. (2019). Transtornos mentais comuns em quilombolas baianos, nordeste brasileiro. Psicologia, Saúde E̊ Doenças, 20(3), 698-710. doi: 10.15309/19psd200312

Nascimento, L. A. \& Leão, A. (2019). Estigma social e estigma internalizado: a voz das pessoas com transtorno mental e os enfrentamentos necessários. História, Ciências, Saúde-Manguinhos, 26(1), 103-121. https://doi.org/10.1590/s0104-59702019000100007

Netto, C. \& Alves, F. (2012). A experiência subjetiva com a doença mental: o caso da depressão. Sociologia, Problemas e Práticas, 70(1), 111-129. http://dx.doi.org/10.7458/ SPP2012701213.

Sardinha, A. H. D. L., Aragão, F. B. A., Silva, C. M., Rodrigues, Z. M. R., Reis, A. D., \& Varga, I. V. D. (2019). Qualidade de vida em idosos quilombolas no nordeste brasileiro. Revista Brasileira de Geriatria e Gerontologia, 22(3), e190011.10.1590/1981-22562019022.190011

Silva, L. L. \& Andrade, E. A. (2018). Autonomia no campo da saúde mental: uma revisão da literatura nacional. Revista Família, Ciclos de Vida e Saúde no Contexto Social, 6(Supl. 1), 347-356. $\underline{10.18554 / \text { refacs.v6io.2921 }}$

Silva, N. G., Barros, S., Azevedo, F. C. D., Batista, L. E., \& Policarpo, V. C. (2017). O quesito raça/cor nos estudos de caracterização de usuários de Centro de Atenção Psicossocial. Saúde e Sociedade, 26 (1)100-1 14. Doi: 10.1590/So104-12902017164968 
Tonin, C. F. \& Barbosa, T. M. (2018). A interface entre Saúde Mental e Vulnerabilidade Social. Tempus Actas de Saúde Coletiva, 1 1(3), 50-68. doi:10.18569/tempus.v1 113.2281

Veiga, L. M. (2019). Descolonizando a psicologia: notas para uma Psicologia Preta. Fractal: Revista de Psicologia, 31(nspe.), 244-248.doi:10.22409/1984-0292/v31i esp/29000.

Viapiana, V. N., Gomes, R. M., \& Albuquerque, G. S. C. D. (2018). Mental illness on contemporary society: conceptual notes on the theory of social determination of the health-disease process. Saúde em Debate, 42(nspe 4), 175-186. doi: https://doi.org/10.1590/0103-11042018S414 Zambillo, M., Palombini, A. D. L., \& Ecker, D. D. I. (2018). Paradoxos nos "benefícios" aos incapacitados: biopolítica e saúde mental. Estudos de Psicologia (Natal), 23(4), 416-426. doi: $\underline{10.22491 / 1678-4669.20180039}$

\section{DANILA CRISTINY DE ARAÚJO MOURA ACIOLE https://orcid.org/OOOO-0003-3803-3310}

Mestre em Psicologia da Saúde pela Universidade Estadual da Paraíba. Professora e coordenadora do curso de Psicologia da Uninassau Caruaru, Psicóloga e coordenadora da Secretaria Especial da Mulher de Belo Jardim.

Endereço: Rua Coronel Ludugero, 39, Cohab 1, Belo Jardim, Pernambuco, 55158780 .

E-mail: danillamoura@hotmail.com

\section{JOSEVÂNIA DA SILVA \\ https://orcid.org/O000-0003-3344-3791}

Doutora em Psicologia Social pela Universidade Federal da Paraíba. Professora do Programa de Pós-graduação em Psicologia da Saúde e docente adjunta da Universidade Estadual da Paraíba.

E-mail: josevania.psi@gmail.com

\begin{tabular}{|c|c|}
\hline Histórico & $\begin{array}{l}\text { Submissão: 04/10/2019 } \\
\text { Revisão:26/04/2020 } \\
\text { Aceite: 08/05/2020 }\end{array}$ \\
\hline $\begin{array}{l}\text { Contribuição } \\
\text { dos autores }\end{array}$ & $\begin{array}{l}\text { Concepção: D.C.A.M.C.; J.S. } \\
\text { Coleta de dadlos: D.C.A.M.C. } \\
\text { Análise de dadlos: D.C.A.M.C.; J.S. } \\
\text { Elaboração dlo manuscrito: D.C.A.M.C.; J.S. } \\
\text { Revisões críticas de conteúdo intelectual importante: } \\
\text { D.C.A.M.C.; J.S. } \\
\text { Aprovação final do manuscrito: D.C.A.M.C.; J.S. }\end{array}$ \\
\hline $\begin{array}{l}\text { Aprovação, ética } \\
\text { e consentimento }\end{array}$ & $\begin{array}{l}\text { Esta pesquisa foi aprovada pelo Comitê de Ética e Pesquisa do Centro } \\
\text { de Ensino Superior e Desenvolvimento- CESED/PB, sob o parecer } \\
\text { n. } 2.925 .682 \text {. }\end{array}$ \\
\hline Financiamento & Não houve financiamento. \\
\hline
\end{tabular}

